\title{
Potentiometric determination of novel complexes of selected lanthanide ions with $N, N^{\prime}$-bis(5-methylsalicylidene)-4-methyl-1,3-phenylenediamine
}

\author{
Małgorzata T. Kaczmarek ${ }^{1} \cdot$ Michał Zabiszak $^{1} \cdot$ Martyna Nowak $^{1} \cdot$ Renata Jastrzab $^{1}$
}

Received: 8 June 2017 / Accepted: 14 November 2017 / Published online: 20 November 2017

(c) The Author(s) 2017. This article is an open access publication

\begin{abstract}
The stability constants of the complexes formed in the $N, N$ '-bis(5-methylsalicylidene)-4-methyl-1,3-phenylenediamine $\left(\mathrm{H}_{2} \mathrm{~L}\right)$ and $\mathrm{La}(\mathrm{III}), \mathrm{Eu}(\mathrm{III}), \mathrm{Gd}(\mathrm{III}), \mathrm{Ho}(\mathrm{III})$, and $\mathrm{Lu}(\mathrm{III})$ ion systems were determined in solution with the potentiometric method. The $\mathrm{pH}$-metric titrations were performed in dimethyl sulfoxide/water (v:v, 30:70) mixture at $25.0{ }^{\circ} \mathrm{C}$ in $0.1 \mathrm{M} \mathrm{LiNO}_{3}$ ionic strength. The tests were performed for systems with $\mathrm{Ln}(\mathrm{III})$ to $\mathrm{H}_{2} \mathrm{~L} 1: 2$ and 1:3 molar ratio but only data of the systems with the metal/ligand ratio 1:2 were taken into calculation. The molar ratio 1:1 was not studied because of the high coordination numbers of the lanthanide ions, and inadequate donor atoms of the ligand. Computer analysis (HYPERQUAD software) of potentiometric data indicated that in solution the lanthanide $(\mathrm{Ln})$ complexes exist as $\mathrm{LnL}_{2}, \mathrm{Ln}(\mathrm{HL})_{2}$, and $\operatorname{Ln}\left(\mathrm{H}_{2} \mathrm{~L}\right)_{2}$ forms, depending on $\mathrm{pH}$ unlike to the solid state where only one form of $\mathrm{Ln}\left(\mathrm{H}_{2} \mathrm{~L}\right)_{2}$ occurs. Formation constants increase with decreasing size of the $\mathrm{Ln}(\mathrm{III})$ ions. Moreover, complex formation in the $\mathrm{Ln}^{3+} / \mathrm{H}_{2} \mathrm{~L}$ systems in solution was performed using UV-Vis spectrophotometric titration.
\end{abstract}

Keywords Potentiometry $\cdot$ Schiff-base complexes $\cdot$ Lanthanides $\cdot$ UV-Vis Spectrophotometric titration

\section{Introduction}

Schiff-base ligands attract the attention of researchers because of their antitumor, antibacterial, antivirus, and antifungal activity which is improved by coordinating ligands to a metal ion [1-3]. Moreover, transition metal complexes with salen-type ligands have applications in heterogenous and homogenous catalysis [4-7], diagnostic pharmaceuticals and laser technology [8]. An additional reason for the current interest in Schiff-base complexes derives from their magnetic and optical properties [9]. The unique properties of lanthanide complexes qualify them for use as magnetic materials, e.g., lanthanide ions are particularly suitable for the synthesis of $4 \mathrm{f}$ single-molecule magnets (SMM)

Electronic supplementary material The online version of this article (https://doi.org/10.1007/s13738-017-1241-7) contains supplementary material, which is available to authorized users.

Renata Jastrzab

renatad@amu.edu.pl

1 Faculty of Chemistry, Adam Mickiewicz University, Umultowska 89b, 61-614 Poznań, Poland
[10-17]. Aza-containing Schiff's base can be used as a neutral ion carrier of a highly selective $\mathrm{Ln}^{3+}$-PVC membrane electrode [18]. Lanthanide ions indicate high coordination numbers, variable, and flexible coordination environments $[19,20]$. Schiff-base salen-type ligands are very flexible compounds, and the combination of these species has great potential in the synthesis of novel and unusual coordination compounds of mononuclear [21,22], polynuclear [23] or polymer [24-27]—type complexes.

The potential applications of Schiff-base lanthanide complexes, especially the unique biological [28] and diagnostic [29] activities associated with them, encouraged us to continue our studies of these compounds.

In this paper by using potentiometry, we determined the stability constants of the complexes formed in the systems $N, N$ '-bis(5-methylsalicylidene)-4-methyl-1,3-phenylenediamine $\left(\mathrm{H}_{2} \mathrm{~L}\right.$, Fig. 1) with the lanthanide $\left(\mathrm{La}^{3+}, \mathrm{Eu}^{3+}, \mathrm{Gd}^{3+}\right.$, $\mathrm{Ho}^{3+}$ and $\mathrm{Lu}^{3+}$ ) ions in dimethyl sulfoxide/water (v:v, 30:70) mixture at $25.0^{\circ} \mathrm{C}$ and $I=0.1 \mathrm{~mol} . \mathrm{dm}^{-3} \mathrm{LiNO}_{3}$. 


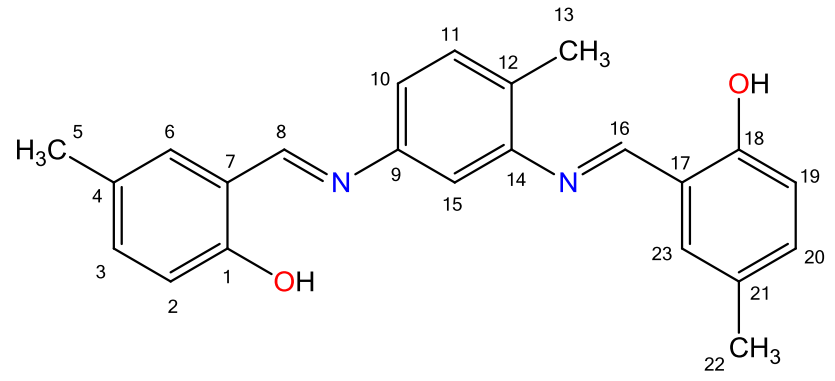

Fig. 1 Formula of $N, N^{\prime}$-bis(5-methylsalicylidene)-4-methyl-1,3-phenylenediamine $\left(\mathrm{H}_{2} \mathrm{~L}\right)$

\section{Experimental}

Lanthanum(III), europium(III), gadolinium(III), holmium(III), and lutetium(III) nitrates,

5-methylsalicylaldehyde and 4-methyl-1,3-phenylenediamine were obtained from the Aldrich Chemical Company. Dimethyl sulfoxide (DMSO) was obtained from the Avantor Performance Materials Poland S.A. (formerly POCH S.A.). The reagents were used without further purification

IR spectra were recorded using $\mathrm{KBr}$ pellets in the range of $4000-400 \mathrm{~cm}^{-1}$ on a Bruker IFS 66v/S spectrophotometer. Mass spectra were performed using electrospray ionization (ESI) techniques. Electrospray mass spectra were determined in methanol using a Waters Micromass ZQ spectrometer. The concentrations of the compounds were approximately $10^{-4} \mathrm{M}$. Sample solutions were introduced into the mass spectrometer source with a syringe pump with a flow rate of $40 \mu \mathrm{L} \mathrm{min}{ }^{-1}$, a capillary voltage of $+3 \mathrm{kV}$ and a desolvation temperature of $300.0^{\circ} \mathrm{C}$. The source temperature was $120.0^{\circ} \mathrm{C}$. The cone voltage $\left(V_{\mathrm{c}}\right)$ was set to $30 \mathrm{~V}$ to allow transmission of ions without fragmentation processes. Scanning was performed from $\mathrm{m} / \mathrm{z}=200-1000$ in $6 \mathrm{~s}$, and 10 scans were summed to obtain the final spectrum. ${ }^{13} \mathrm{C} \mathrm{NMR}$ and ${ }^{1} \mathrm{H} \mathrm{NMR}$ spectra were recorded in $\mathrm{CD}_{2} \mathrm{Cl}_{2}$ on a Varian Gemini 300 spectrometer with chemical shift (ppm) reported relative to TMS as an internal reference. Electronic absorption spectra were measured on a JASCO V-550 spectrophotometer in ethanol and dimethyl sulfoxide. Microanalyses $(\mathrm{CHN})$ were obtained using a PerkinElmer $2400 \mathrm{CHN}$ microanalyzer.

All experiments were prepared using dimethyl sulfoxide/ water 30:70 (v/v) solution (demineralised $\mathrm{CO}_{2}$-free water was used). The concentration of metal ions was determined by inductively coupled plasma optical emission spectrometry (ICP OES). Potentiometric titrations were carried out using a Titrino 702 Metrohm equipped with an autoburette with a Metrohm Solvotrode combination $\mathrm{pH}$ glass electrode specially designed for use with nonaqueous acid-base titrations, calibrated prior to each titration [30].
A correction of the $\mathrm{pH}$-meter reading was made prior to each measurement series, and two standard buffers were used ( $\mathrm{pH} 4.002$ and $\mathrm{pH} 9.225)$. All potentiometric titrations were made in an atmosphere of neutral gas (helium 5.0) at a constant ionic strength $\left(0.1 \mathrm{M} \mathrm{LiNO}_{3}\right)$, at $25.0{ }^{\circ} \mathrm{C}$ using $\mathrm{CO}_{2}$-free $\mathrm{NaOH}$ as a titrant at a concentration of $0.1823 \mathrm{M}$, the concentration of solution of $\mathrm{NaOH}$ was determined by inductively coupled plasma optical emission spectrometry (ICP OES). The concentration of the ligand was $1 \times 10^{-3} \mathrm{M}$, and $\mathrm{HCl}$ was added to the systems $(1.5 \mathrm{ml} ; 0.1 \mathrm{M})$. The metal to ligand ratios was $1: 2$ and $1: 3$, but only data of the systems with the metal/ligand ratio 1:2 were taken into calculation because at a molar ratio higher than $1: 2$ a precipitate of complexes were obtained. The molar ratio 1:1 was not studied due to the tendency of lanthanide ions to achieve high coordination numbers, and inadequate number of donor atoms of the ligand. Determined $p K_{w}$ for dimethyl sulfoxide/ water (30:70) was 14.501 [31]. The protonation constants of the $N, N$ '-bis(5-methylsalicylidene)-4-methyl-1,3-phenylenediamine, the selection of the models as well as the stability constants of the complexes were determined with HYPERQUAD software which uses the nonlinear method of least squares [32]. Distribution of respective forms was obtained by applying the HySS (Hyperquad Simulation and Speciation) program [33]. The calculations were performed using 150-350 points for each job taking into account only the part of the titration where no precipitate occurred. In all cases, the testing began with the simplest hypothesis, and then in the following steps, the models were expanded to include progressively more species. The results were scrutinized to eliminate the species that were rejected in the refinement procedures. The criteria used for verification of results are given in an earlier paper [34, 35].

Samples for electronic spectra were prepared in dimethyl sulfoxide $/ \mathrm{H}_{2} \mathrm{O}(30: 70 \mathrm{v} / \mathrm{v})$ solution, acidified with $\mathrm{HCl}$ $(1.5 \mathrm{ml} ; 0.1 \mathrm{M})$ at $\mathrm{Ln}^{3+}: \mathrm{H}_{2} \mathrm{~L} 1: 2$ ratio. Concentration of ligand $\mathrm{H}_{2} \mathrm{~L}$ was $1 \times 10^{-4} \mathrm{M}$. The spectra were recorded at $20.0{ }^{\circ} \mathrm{C}$ in a quartz cell with a $1 \mathrm{~cm}$ path length on an Evolution $300 \mathrm{UV}-\mathrm{Vis}$ ThermoFisher Scientific spectrometer equipped with a xenon lamp (range 250-500 nm, accuracy $0.2 \mathrm{~nm}$, sweep rate $\left.120 \mathrm{~nm} \mathrm{~min}{ }^{-1}\right)$. UV-Vis spectra were measured in $\mathrm{pH}$ intervals, from 3 to 10 .

Synthesis of $N, N$ '-bis(5-methylsalicylidene)-4-methyl1,3-phenylenediamine $\left(\mathrm{H}_{2} \mathrm{~L}\right)$

The N,N'-bis(5-methylsalicylidene)-4-methyl-1,3-phenylenediamine $\left(\mathrm{H}_{2} \mathrm{~L}\right)$ was prepared according to reported procedure [36] and was obtained from the condensation reaction of 5-methylsalicylaldehyde $(27 \mathrm{mg}, 0.2 \mathrm{mmol})$ and 4-methyl-1,3-phenylenediamine (12 mg, $0.1 \mathrm{mmol}$ ) in a 2:1 molar ratio of substrates. The mixture was stirred in ethanol $(30 \mathrm{~mL})$ at room temperature for $24 \mathrm{~h}$. The yellow solution was concentrated to half of its initial volume and allowed to crystallize. The crystals formed were collected, washed with 
cold ethanol and dried in air. Yield: $31.6 \mathrm{mg}(89.0 \%)$. Anal. Calcd for $\mathrm{C}_{23} \mathrm{H}_{22} \mathrm{~N}_{2} \mathrm{O}_{2}: \mathrm{C}, 77.07 ; \mathrm{H}, 6.16 ; \mathrm{N}, 7.82 \%$. Found: C, 76.92; H, 6.10; N, 7.74. ESI-MS: $m / z 359\left(\mathrm{M}^{+}, 100 \%\right)$. M.p.: $144.0{ }^{\circ} \mathrm{C} .{ }^{1} \mathrm{H}$ NMR and COSY NMR $\left(300 \mathrm{~Hz} ; \mathrm{CD}_{2} \mathrm{Cl}_{2}\right.$; $\mathrm{Me}_{4} \mathrm{Si}, \delta_{H}$ ) 12.97, 12.92 (two s, H-1, H-18, 2OH), 8.66, 8.61 (two s, H-8, H-16, 2HC=N), $7.32(d, J=8.3 \mathrm{~Hz}, \mathrm{H}-10$, Ar-H), 7.25 (dd, $J=11.3 \mathrm{~Hz}, \mathrm{H}-3, \mathrm{H}-20, \mathrm{Ar}-\mathrm{H}), 7.20$ (dd, $J=8.0 \mathrm{~Hz}, \mathrm{H}-2, \mathrm{H}-19, \mathrm{Ar}-\mathrm{H}), 7.14$ (dd, $J=8.0 \mathrm{~Hz}, \mathrm{H}-15$, $\mathrm{Ar}-\mathrm{H}), 7.08(d, J=2.1 \mathrm{~Hz}, \mathrm{H}-11, \mathrm{Ar}-\mathrm{H}), 6.91(t, J=7.6 \mathrm{~Hz}$, $\mathrm{H}-6, \mathrm{H}-23, \mathrm{Ar}-\mathrm{H}$ ), 2.40 ( $s, 3 \mathrm{H}-13, \mathrm{Ar}^{-} \mathrm{CH}_{3}$ ), 2.33, 2.32 (two $s$, 3H-5, 3H-22, two Ar- $\left.\mathrm{CH}_{3}\right) .{ }^{13} \mathrm{C}$ NMR $\left(300 \mathrm{~Hz} ; \mathrm{CD}_{2} \mathrm{Cl}_{2}\right.$; $\left.\mathrm{Me}_{4} \mathrm{Si}, \delta_{\mathrm{C}}\right) 162.83,162.32,158.99,158.89,148.44,147.58$, $134.30,134.11,132.32,132.22,131.44,131.01,128.25$, $118.83,118.75,118.67,116.99,116.97,111.05,20.34$, 17.88. FT-IR $\left(\mathrm{KBr}, \mathrm{cm}^{-1}\right): \nu(\mathrm{O}-\mathrm{H}) 3379, \nu(\mathrm{O}-\mathrm{H} \ldots \mathrm{N}) 2701$, $\nu(\mathrm{C}=\mathrm{N}) 1621, \nu(\mathrm{C}-\mathrm{O}) 1283, \nu(\mathrm{C}=\mathrm{C}) 1488,781,671$.

\section{Results and discussion}

$N, N$ '-bis(5-methylsalicylidene)-4-methyl-1,3-phenylenediamine ligand $\left(\mathrm{H}_{2} \mathrm{~L}\right)$ (Fig. 1) was obtained in a condensation reaction, and single crystals suitable for $\mathrm{X}$-ray analysis were obtained by slow evaporation of the solvent [36]. Due to the insolubility of that type of ligand in water, the potentiometry studies were performed in mixtures of organic solvents, e.g., dimethyl sulfoxide [37], methanol [38], ethanol [39] or dioxane [40] with water. Our research led to the selection of a mixture of the dimethyl sulfoxide water 30:70 (v/v) [41].

\section{Potentiometric measurements}

The formation of complexes between $N, N$ '-bis(5methylsalicylidene)-4-methyl-1,3-phenylenediamine ligand $\left(\mathrm{H}_{2} \mathrm{~L}\right)$ and $\mathrm{La}^{3+}, \mathrm{Eu}^{3+}, \mathrm{Gd}^{3+}, \mathrm{Ho}^{3+}$, and $\mathrm{Lu}^{3+}$ ions $\left(\mathrm{Ln}^{3+}\right)$ was studied by $\mathrm{pH}$-metry titration. Potentiometric titration was performed in dimethyl sulfoxide/water 30:70 (v/v) mixture $\left(p K_{w}=14.501\right)$. As it is shown in Fig. 2, three protonation constants were determined from computer analysis of the titration data: $\log K_{1}=10.05, \log K_{2}=8.49$ and $\log K_{3}=5.45$ for $N, N^{\prime}$-bis(5-methylsalicylidene)-4-methyl-1,3-phenylenediamine.

The values received for the ionization constants were in consistent with those obtained previously for similar compounds such as $N, N$ '-bis(salicylidene)-4-methyl1,3 -phenylenediamine $\left(\log K_{1}=8.54, \log K_{2}=6.36\right.$ and $\log K_{3}=5.54$ ) [41]. The increase in the value of ionization constants as compared with our earlier investigation is due to the inductive electron-donor effect of the next methyl substituent on the aromatic ring [37, 41]. $N, N$ 'bis(5-methylsalicylidene)-4-methyl-1,3-phenylenediamine ligand $\left(\mathrm{H}_{2} \mathrm{~L}\right)$ occurs in solution in three forms: unionized (neutral, $\mathrm{H}_{2} \mathrm{~L}$ ), partially $\left(\mathrm{HL}^{-}\right)$, and fully $\left(\mathrm{L}^{2-}\right)$ deprotonated

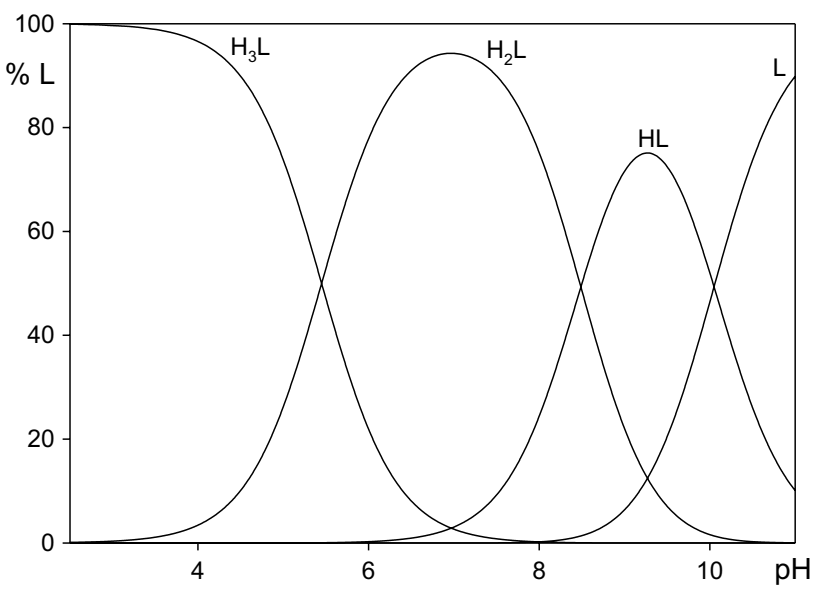

Fig. 2 Species distribution diagrams of the $N, N^{\prime}$-bis(5methylsalicylidene)-4-methyl-1,3-phenylenediamine $\left(\mathrm{H}_{2} \mathrm{~L}\right)$, solvent $\mathrm{DMSO} / \mathrm{H}_{2} \mathrm{O}(30 / 70, \mathrm{v} / \mathrm{v})$

depending on $\mathrm{pH}$. The species distribution diagram of $\mathrm{H}_{2} \mathrm{~L}$ ligand shows that in the $\mathrm{pH}$ range 5-8 the form $\mathrm{H}_{2} \mathrm{~L}$ dominated but in the $\mathrm{pH}$ range 9-11 the three forms $\mathrm{H}_{2} \mathrm{~L}, \mathrm{HL}^{-}$, and $\mathrm{L}^{2-}$ coexist. Values $\log K_{1}=10.05$, and $\log K_{2}=8.49$ correspond to protonation of the phenolic groups, whereas $\log K_{3}=5.45$ corresponds to protonation of an imine nitrogen $[1,37,41]$.

The stability constants $(\log \beta)$ and equilibrium constants $(\log K)$ of the complexes formed in the $\mathrm{Ln}^{3+} / \mathrm{H}_{2} \mathrm{~L}$ systems are listed in Table 1 . The model assumed was verified by analysis of the standard deviations and the convergence of the experimental data with a theoretical curve obtained for the chosen model (evaluated by the Hamiltonian test and Chi-squared tests). For the sake of simplicity, ion charges in potentiometric description of the complexes were omitted.

The complexes of $\mathrm{Ln}\left(\mathrm{H}_{2} \mathrm{~L}\right)_{2}, \mathrm{Ln}(\mathrm{HL})_{2}$, and $\mathrm{LnL}_{2}$ type are observed for all systems (Fig. 3). All these species exist in solution up to $\mathrm{pH}$ 8. Precipitation occurs above this $\mathrm{pH}$ value.

Complex formation in solution starts at $\mathrm{pH} 4.5$ for the $\mathrm{La}^{3+}, \mathrm{Eu}^{3+}$ systems and $\mathrm{pH} 4.0$ for the $\mathrm{Gd}^{3+}, \mathrm{Ho}^{3+}$, and $\mathrm{Lu}^{3+}$ system formation of $\mathrm{Ln}\left(\mathrm{H}_{2} \mathrm{~L}\right)_{2}$ complexes with two unionized (neutral) ligands. The equilibrium constants of $\mathrm{Ln}\left(\mathrm{H}_{2} \mathrm{~L}\right)_{2}$ formation were calculated according to the reaction and formula:

$2 \mathrm{H}_{2} \mathrm{~L}+\mathrm{Ln}^{3+} \leftrightarrows \mathrm{Ln}\left(\mathrm{H}_{2} \mathrm{~L}\right)_{2}$

$\log K_{\mathrm{Ln}\left(\mathrm{H}_{2} \mathrm{~L}\right) 2}=\log \beta_{\mathrm{Ln}\left(\mathrm{H}_{2} \mathrm{~L}\right) 2}-2 \log \beta$

and are 5.70, 5.66, 6.43, 6.59, and 6.81 for $\mathrm{La}^{3+}, \mathrm{Eu}^{3+}, \mathrm{Gd}^{3+}$, $\mathrm{Ho}^{3+}$ and $\mathrm{Lu}^{3+}$, respectively (Table 1 ). The stability constants of $\mathrm{Ln}\left(\mathrm{H}_{2} \mathrm{~L}\right)_{2}$ are 42.78, 42.74, 43.51, 43.67, and 43.89 for $\mathrm{La}^{3+}, \mathrm{Eu}^{3+}, \mathrm{Gd}^{3+}, \mathrm{Ho}^{3+}$, and $\mathrm{Lu}^{3+}$, respectively. 
Table 1 Stability constants (log $\beta)$ and equilibrium constants $\left(\log K_{e}\right.$ ) of complexes formed in the $\mathrm{Ln}^{3+} / \mathrm{H}_{2} \mathrm{~L}$ systems (standard deviations of stability constants are given in brackets)

\begin{tabular}{|c|c|c|c|c|c|c|c|c|c|c|}
\hline & \multicolumn{2}{|l|}{$\mathrm{La}^{3+} / \mathrm{H}_{2} \mathrm{~L}$} & \multicolumn{2}{|l|}{$\mathrm{Eu}^{3+} / \mathrm{H}_{2} \mathrm{~L}$} & \multicolumn{2}{|l|}{$\mathrm{Gd}^{3+} / \mathrm{H}_{2} \mathrm{~L}$} & \multicolumn{2}{|c|}{$\mathrm{Ho}^{3+} / \mathrm{H}_{2} \mathrm{~L}$} & \multicolumn{2}{|l|}{$\mathrm{Lu}^{3+} / \mathrm{H}_{2} \mathrm{~L}$} \\
\hline & $\log \beta$ & $\log K_{e}$ & $\log \beta$ & $\log K_{e}$ & $\log \beta$ & $\log K_{e}$ & $\log \beta$ & $\log K_{e}$ & $\log \beta$ & $\log K_{e}$ \\
\hline $\mathrm{M}\left(\mathrm{H}_{2} \mathrm{~L}\right)_{2}$ & $42.78(8)$ & 5.70 & $42.74(8)$ & 5.66 & $43.51(5)$ & 6.43 & $43.67(7)$ & 6.59 & $43.89(5)$ & 6.81 \\
\hline $\mathrm{M}(\mathrm{HL})_{2}$ & $28.79(7)$ & 8.69 & $28.77(4)$ & 8.67 & 29.71(4) & 9.61 & $30.28(8)$ & 10.18 & $30.68(4)$ & 10.58 \\
\hline $\mathrm{ML}_{2}$ & $12.28(6)$ & 12.28 & $12.29(6)$ & 12.29 & $13.51(6)$ & 13.51 & $13.42(8)$ & 13.42 & $15.12(5)$ & 15.12 \\
\hline
\end{tabular}

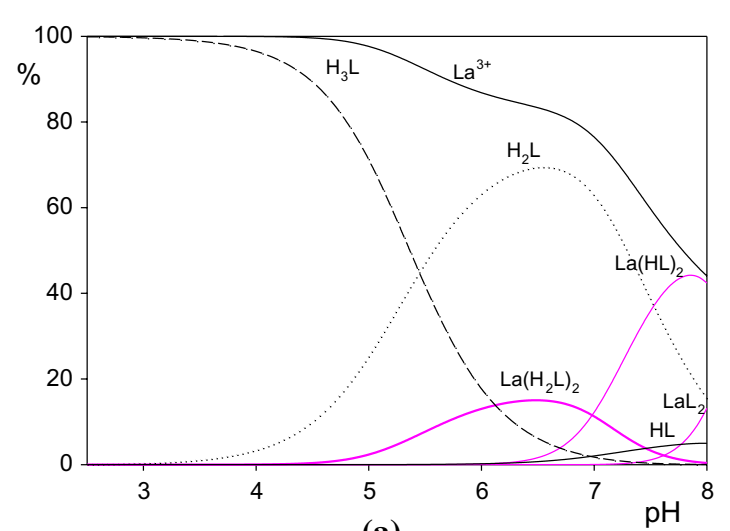

(a)

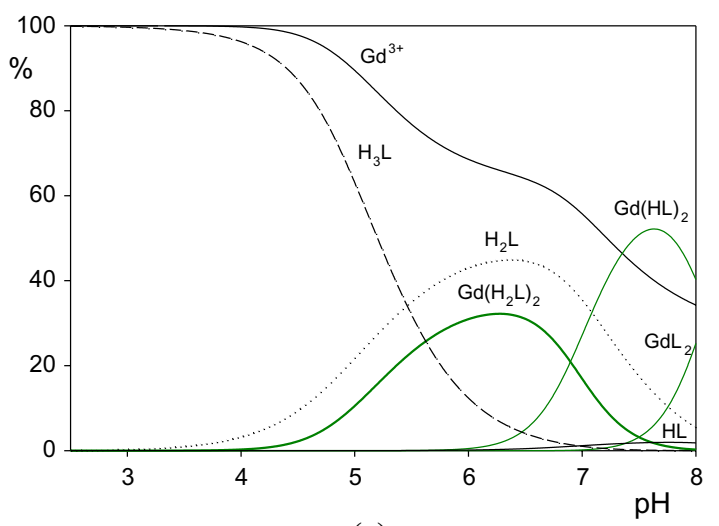

(c)
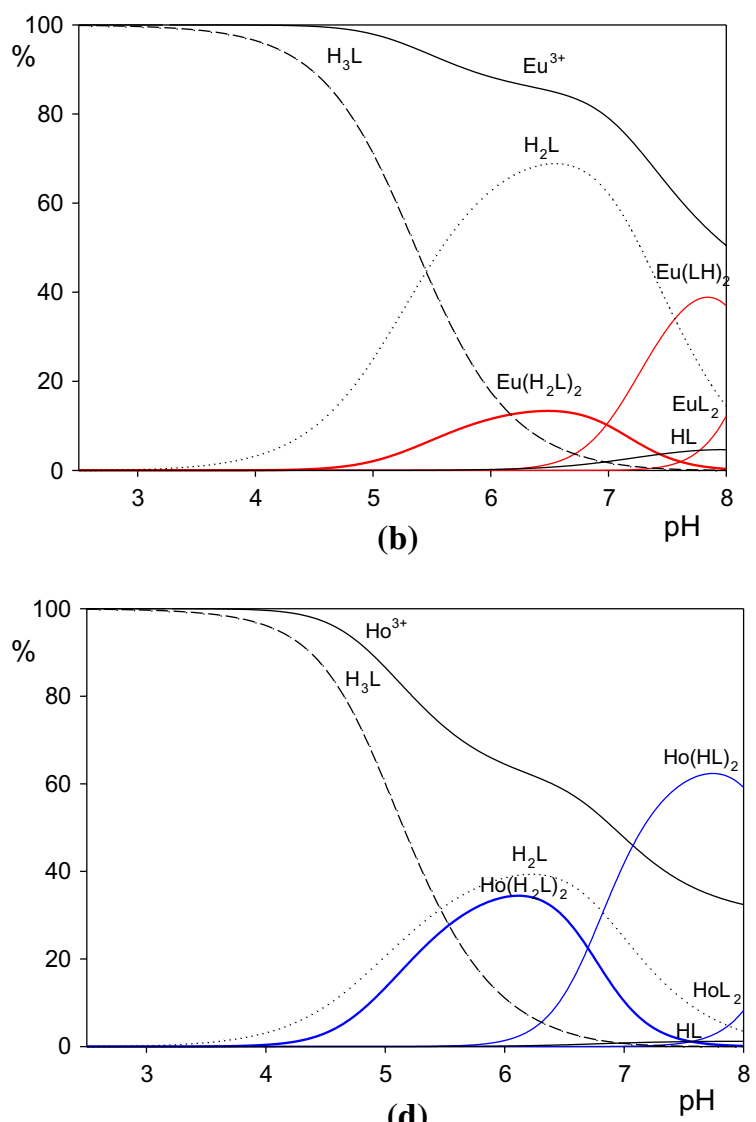

(d)

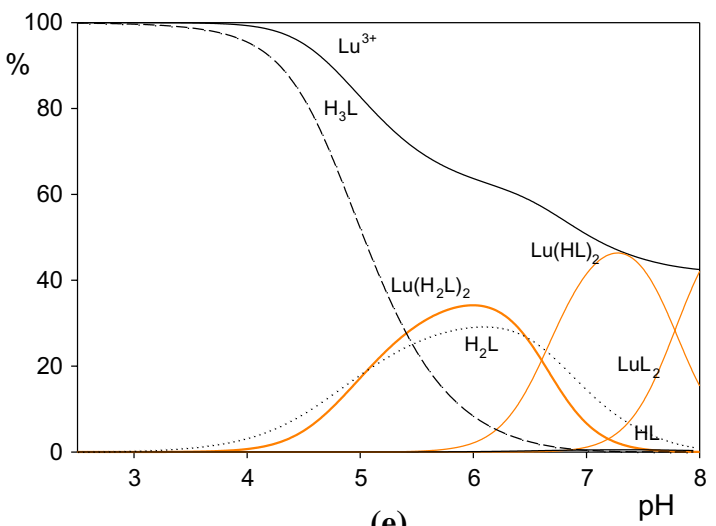

(e)

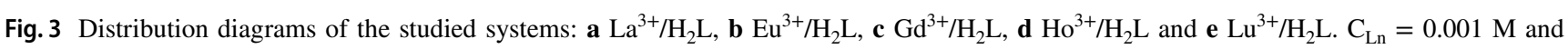
$\mathrm{C}_{\mathrm{H}_{2} \mathrm{~L}}=0.002 \mathrm{M}$ 
$\mathrm{Ln}(\mathrm{HL})_{2}$ species with two monoprotonated ligands are formed at a $\mathrm{pH}$ in which the ligand $\mathrm{H}_{2} \mathrm{~L}$ is partly deprotonated, and the lanthanide(III) ion is connected to this form. The equilibrium constants of $\mathrm{Ln}(\mathrm{HL})_{2}$ formation were calculated according to the reaction $\mathrm{H}_{2} \mathrm{~L} \leftrightarrows \mathrm{HL}+\mathrm{H}$ and $2 \mathrm{HL}+\mathrm{Ln} \leftrightarrows \mathrm{Ln}(\mathrm{HL})_{2}$. Coordination of these types of complex begins at pH 6.0 for $\mathrm{La}^{3+}$ and $\mathrm{Eu}^{3+}$ during for $\mathrm{Gd}^{3+}$, $\mathrm{Ho}^{3+}$, and $\mathrm{Lu}^{3+}$ at $\mathrm{pH}$ 5.5. The equilibrium constants of formation of $\mathrm{Ln}(\mathrm{HL})_{2}$ were calculated according to the formula:

$\log K_{\mathrm{Ln}(\mathrm{HL}) 2}=\log \beta_{\mathrm{Ln}(\mathrm{HL}) 2}-2 \log _{\mathrm{HL}}$

and are 8.69, 8.67, 9.61, 10.18, and 10.58 for $\mathrm{La}^{3+}, \mathrm{Eu}^{3+}$, $\mathrm{Gd}^{3+}, \mathrm{Ho}^{3+}$, and $\mathrm{Lu}^{3+}$, respectively, indicating the similar stability of these complex species for all lanthanides complexes (Table 1). The stability constants of $\mathrm{Ln}(\mathrm{HL})_{2}$ are 28.79, 28.77, 29.71, 30.28, and 30.68 for $\mathrm{La}^{3+}, \mathrm{Eu}^{3+}, \mathrm{Gd}^{3+}$, $\mathrm{Ho}^{3+}$ and $\mathrm{Lu}^{3+}$, respectively (Table 1 ).

Finally, $\mathrm{LnL}_{2}$ complexes are formed as the result of total ligand deprotonation according to $\mathrm{HL} \leftrightarrows \mathrm{L}+\mathrm{H}$ and $2 \mathrm{~L}+\mathrm{Ln} \leftrightarrows \mathrm{LnL}_{2}$ equilibria. These complexes start to form at $\mathrm{pH} 7.5$ for $\mathrm{La}^{3+}, \mathrm{Eu}^{3+}$, and $\mathrm{Ho}^{3+}$ ions and at $\mathrm{pH} 7.0$ for $\mathrm{Gd}^{3+}$ and $\mathrm{Lu}^{3+}$ ions. The stability constants of $\mathrm{LnL}_{2}$ are $12.28,12.29,13.51,13.42$, and 15.12 for $\mathrm{La}^{3+}, \mathrm{Eu}^{3+}, \mathrm{Gd}^{3+}$, $\mathrm{Ho}^{3+}$, and $\mathrm{Lu}^{3+}$, respectively (Table 1 ). The excellent agreement between the experimental and theoretical curves (Fig. S1) indicates the presence of only the 1:2 molar ratio complexes such as $\operatorname{Ln}\left(\mathrm{H}_{2} \mathrm{~L}\right)_{2}, \mathrm{Ln}(\mathrm{HL})_{2}$, and the $\mathrm{LnL}_{2}$ type.

The stability constants of the $\operatorname{Ln}\left(\mathrm{H}_{2} \mathrm{~L}\right)_{2}, \mathrm{Ln}(\mathrm{HL})_{2}$, and $\mathrm{LnL}_{2}$ complexes fall into the following order: $\mathrm{La} \approx \mathrm{Eu}<\mathrm{Gd}<\mathrm{Ho}<\mathrm{Lu}$ which reflect the size of the lanthanide ions. This can be attributed to the change of properties of lanthanide ions, not only for stabilities but also for structural changes of lanthanide compounds. These properties are associated with the systematic decrease of an ionic radius with an increasing atomic number of lanthanides which is correlated with the lanthanide contraction [42]. As a result, the coordination number of the lanthanide ions decreases along a series: For the light lanthanides (La-Dy), this is preferably 10 or 9 , while for the heavy lanthanides (Ho-Lu) it is 9 or 8 (sometimes even 7) [43-47]. Comparison of stability constants determined for the all systems studied: $\mathrm{Ln}\left(\mathrm{H}_{2} \mathrm{~L}\right)_{2}$, $\mathrm{Ln}(\mathrm{HL})_{2}$, and $\mathrm{LnL}_{2}$ reveals that the highest values are for $\mathrm{Ln}\left(\mathrm{H}_{2} \mathrm{~L}\right)_{2}$ complexes. Our previous investigations showed that only complexes with a unionized (neutral) ligand formed well-defined crystals [45, 46]. In the solid state, two types of complexes of general formulae $\left[\mathrm{Ln}\left(\mathrm{H}_{2} \mathrm{~L}\right)_{3}\left(\mathrm{NO}_{3}\right)_{3}\right]$ $(\mathrm{Ln}=\mathrm{La}, \mathrm{Eu}, \mathrm{Tb})$ and $\left[\mathrm{Ln}\left(\mathrm{H}_{2} \mathrm{~L}\right)_{2}\left(\mathrm{NO}_{3}\right)_{3} \mathrm{EtOH}\right] \mathrm{MeOH}$ $(\mathrm{Ln}=\mathrm{Er}, \mathrm{Tm})$ were obtained. In the complexes formed in solution, it is likely that coordination spheres of light lanthanide ions are complemented by a solvent and not by a ligand molecule as in solid state. The lower stability constants of the $\mathrm{Ln}(\mathrm{HL})_{2}$, and $\mathrm{LnL}_{2}$ complexes (lower volume of stability constants) cause these species to form only in solution.
Comparison of the equilibrium constants determined for the presented systems with those obtained previously for similar systems Ln/ $N, N$ '-bis(salicylidene)-4-methyl-1,3-phenylenediamine shows that additional methyl substituent on the ligands affects the volume of the stability constants of the complexes [41]. The presence of third methyl groups significantly decreases the equilibrium constants of the studied complexes (Fig. 4).

\section{Electronic spectroscopy}

The sensing behavior of the $N, N$ '-bis(5-methylsalicylidene)4-methyl-1,3-phenylenediamine ligand $\left(\mathrm{H}_{2} \mathrm{~L}\right)$ toward $\mathrm{Ln}^{3+}$ was monitored by UV-Vis spectrophotometric titration. The titration was carried out in a dimethyl sulfoxide/water 30:70 $(\mathrm{v} / \mathrm{v})$ mixture at a concentration of $\mathrm{H}_{2} \mathrm{~L} 1 \times 10^{-4} \mathrm{M}$. Spectrophotometric titration spectra were collected from $\mathrm{pH} 3$ to 10 covering a wavelength range of $250-500 \mathrm{~nm}$. Figure 5 presents the absorption spectra for one chosen studied system $\left(\mathrm{Gd}^{3+} / \mathrm{H}_{2} \mathrm{~L}\right)$.

Because of $\mathrm{pH}$ domination, the absorption spectra of the complexes for all systems were taken at pH 6 and pH 8 and are presented in Fig. 6. Table 2 summarizes absorption parameters for the studied systems. $\operatorname{Ln}\left(\mathrm{H}_{2} \mathrm{~L}\right)_{2}$ and $\operatorname{Ln}(\mathrm{HL})_{2}$ complexes are the dominant systems at $\mathrm{pH} 6$ and 8, respectively. Spectra of $\mathrm{Ln}\left(\mathrm{H}_{2} \mathrm{~L}\right)_{2}$ and $\mathrm{Ln}(\mathrm{HL})_{2}$ complexes for all systems studied are characterized by three main absorption bands which are assigned to the $\pi-\pi^{*}$ and $n-\pi^{*}$ transitions of the Schiff-base ligand. The $210-300 \mathrm{~nm}$ bands are due to the $\pi-\pi^{*}$ transitions of the aromatic rings. The bands at the $300-350 \mathrm{~nm}$ range are assigned to the $\pi-\pi^{*}$ transitions of the $\mathrm{C}=\mathrm{N}$ group. Maximum absorption of about $380-400 \mathrm{~nm}$ can be assigned to the intramolecular charge transfer interaction.

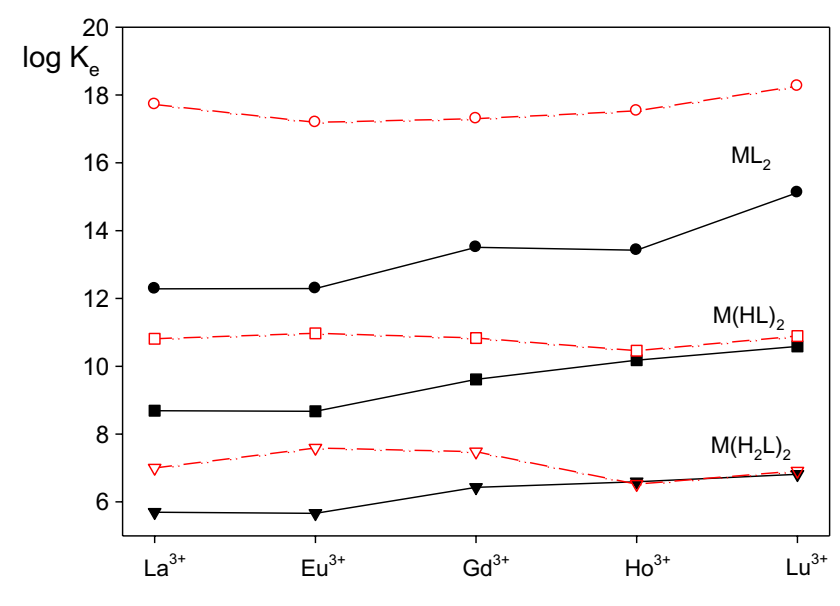

Fig. 4 Comparison of equilibrium constants of $\mathrm{Ln}^{3+} / N, N^{\prime}$-bis(salicylidene)-4-methyl-1,3-phenylenediamine systems (previous investigations) - red line, and $\mathrm{Ln}^{3+} / \mathrm{H}_{2} \mathrm{~L}$ systems-black line 
Fig. 5 3D representing absorption spectrum of $\mathrm{Gd}^{3+} / \mathrm{H}_{2} \mathrm{~L}$ system

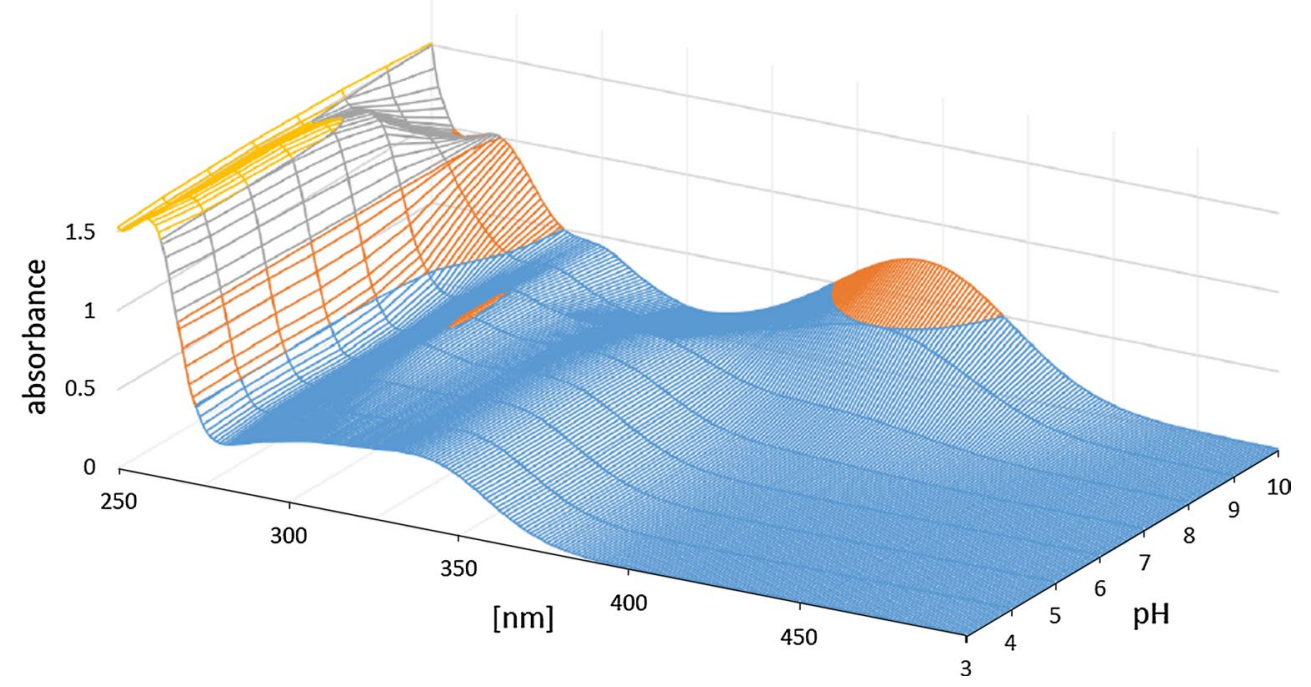

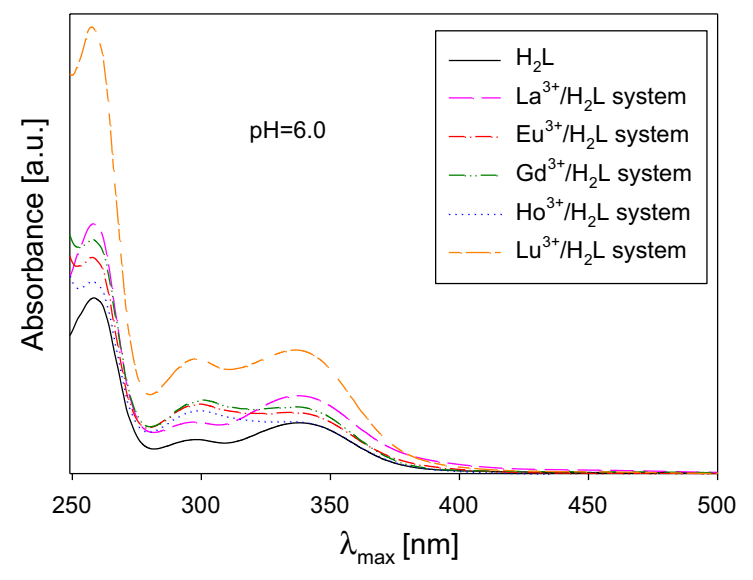

(a)

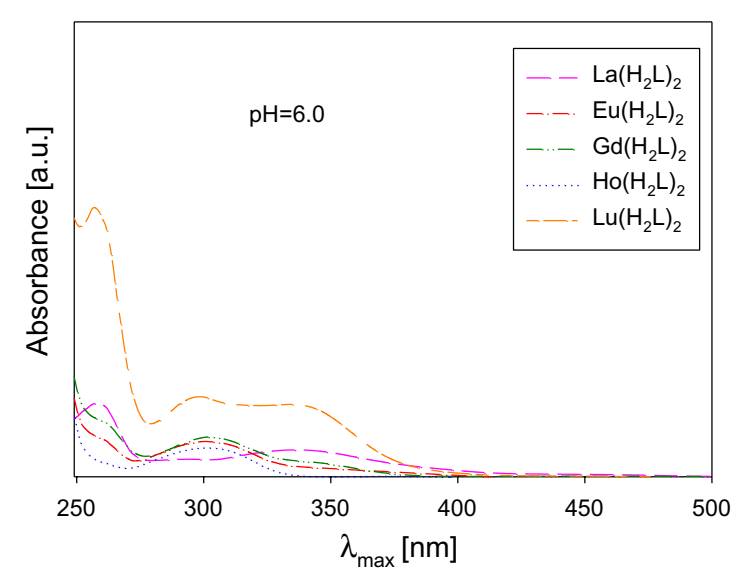

(c)

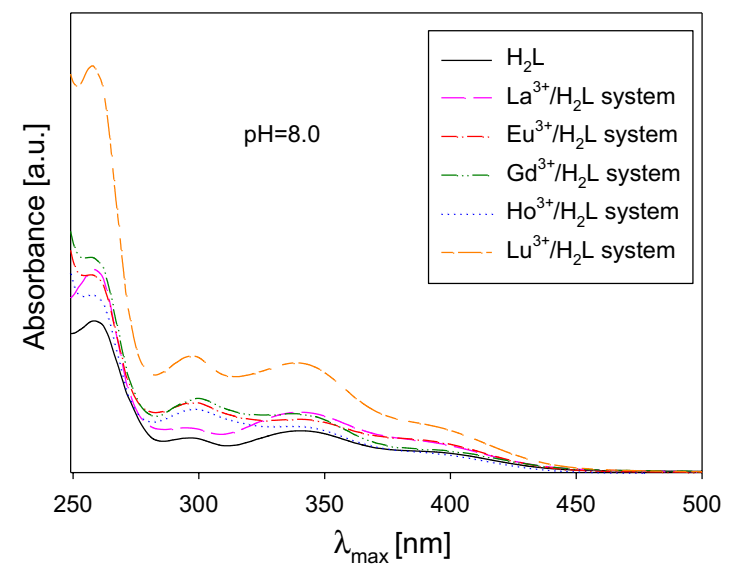

(b)

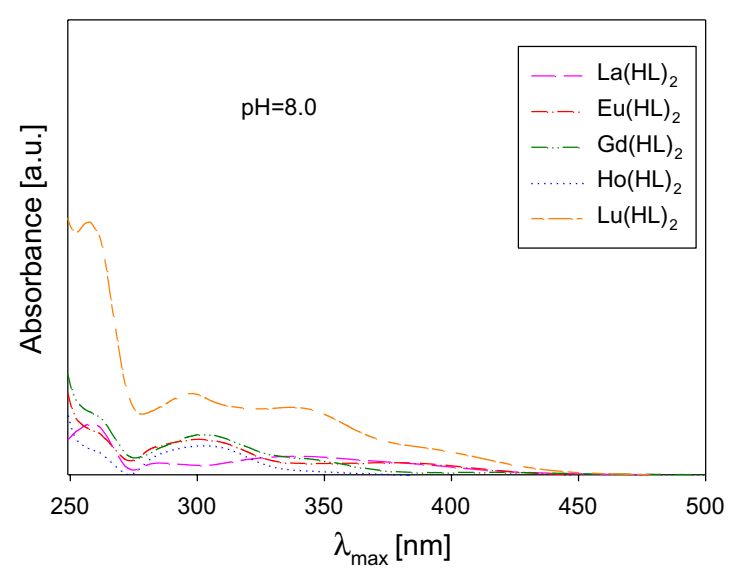

(d)

Fig. 6 UV-Vis absorption spectra of: $\mathbf{a} \mathrm{Ln}^{3+} / \mathrm{H}_{2} \mathrm{~L}$ system at $\mathrm{pH}=6.0, \mathbf{b ~} \mathrm{Ln}^{3+} / \mathrm{H}_{2} \mathrm{~L}$ system at $\mathrm{pH}=8.0$, c $\mathrm{Ln}\left(\mathrm{H}_{2} \mathrm{~L}\right)_{2}$ complexes at $\mathrm{pH}=6.0$, d $\mathrm{Ln}(\mathrm{HL})_{2}$ complexes at $\mathrm{pH}=8.0$ (spectra of complexes were obtained by subtracting the ligand spectrum of $\mathrm{Ln}^{3+} / \mathrm{H}_{2} \mathrm{~L}$ system spectra) 
Table 2 Absorption data for the studied systems at $\mathrm{pH} 6$ and $\mathrm{pH} 8 ; \lambda_{\max }[\mathrm{nm}] ; \varepsilon$ $\left[10^{3} \mathrm{dm}^{3} \mathrm{~mol}^{-1} \mathrm{~cm}^{-1}\right]$

\begin{tabular}{|c|c|c|c|c|c|c|c|c|c|c|c|c|}
\hline & \multicolumn{2}{|l|}{$\mathrm{H}_{2} \mathrm{~L}$} & \multicolumn{2}{|c|}{$\mathrm{La}^{3+} / \mathrm{H}_{2} \mathrm{~L}$} & \multicolumn{2}{|c|}{$\mathrm{Eu}^{3+} / \mathrm{H}_{2} \mathrm{~L}$} & \multicolumn{2}{|c|}{$\mathrm{Gd}^{3+} / \mathrm{H}_{2} \mathrm{~L}$} & \multicolumn{2}{|c|}{$\mathrm{Ho}^{3+} / \mathrm{H}_{2} \mathrm{~L}$} & \multicolumn{2}{|c|}{$\mathrm{Lu}^{3+} / \mathrm{H}_{2} \mathrm{~L}$} \\
\hline & $\lambda_{\max }$ & $\varepsilon$ & $\lambda_{\max }$ & $\varepsilon$ & $\lambda_{\max }$ & $\varepsilon$ & $\lambda_{\max }$ & $\varepsilon$ & $\lambda_{\max }$ & $\varepsilon$ & $\lambda_{\max }$ & $\varepsilon$ \\
\hline \multirow[t]{3}{*}{$\mathrm{pH}=6$} & 258 & 12.73 & 259 & 18.05 & 258 & 15.67 & 258 & 16.98 & 258 & 13.94 & 258 & 32.34 \\
\hline & 298 & 2.46 & 296 & 3.72 & 299 & 5.03 & 300 & 5.33 & 299 & 4.60 & 299 & 8.32 \\
\hline & 338 & 3.67 & 338 & 6.65 & 338 & 4.41 & 338 & 4.83 & 339 & 3.75 & 337 & 8.96 \\
\hline \multirow[t]{4}{*}{$\mathrm{pH}=8$} & 259 & 10.99 & 258 & 14.72 & 258 & 14.32 & 257 & 15.60 & 258 & 12.90 & 258 & 29.47 \\
\hline & 296 & 2.50 & 294 & 3.24 & 299 & 5.08 & 300 & 5.38 & 298 & 4.62 & 298 & 8.44 \\
\hline & 340 & 3.02 & 341 & 4.38 & 342 & 2.85 & 340 & 4.26 & 344 & 3.30 & 340 & 7.95 \\
\hline & 394 & 1.50 & 396 & 2.10 & 388 & 2.39 & 398 & 1.59 & 394 & 1.42 & 391 & 3.46 \\
\hline
\end{tabular}

The maximum absorption of the band $\left(\lambda_{\max }\right)$ in the $\mathrm{Ln}^{3+} / \mathrm{H}_{2} \mathrm{~L}$ systems showed only slight changes but absorption increases compared to the free ligand [48-50]. Furthermore, at $\mathrm{pH} 8$, a new absorption band appears, at $\lambda_{\max }=394 \mathrm{~nm}$ for ligand and about $388-398 \mathrm{~nm}$ for all systems. The new absorption band is formed due to the deprotonation of the phenolic $\mathrm{OH}$ groups of the ligand $\left(\mathrm{H}_{2} \mathrm{~L}\right)$ [51].

The changes described above mainly depended on the type of complexes formed. Moreover, the coordination of the $\mathrm{Ln}^{3+}$ does not significantly influence the singlet-state energy of the ligand. The change of $\mathrm{pH}$ does not cause any significant shift in the spectra of the studied systems because some chromophores were only slightly affected by a $\mathrm{pH}$ change [52].

\section{Conclusions}

The complex formation processes, and the values of stability and equilibrium constants of the complexes of $N, N^{\prime}$ bis(5-methylsalicylidene)-4-methyl-1,3-phenylenediamine $\left(\mathrm{H}_{2} \mathrm{~L}\right)$ with lanthanide ions $\left(\mathrm{La}^{3+}, \mathrm{Eu}^{3+}, \mathrm{Gd}^{3+}, \mathrm{Ho}^{3+}\right.$ and $\mathrm{Lu}^{3+}$ ) were determinated by potentiometric and spectrophotometric titration. The studied complexes are formed in solution only with lanthanide ions/ligand 1:2 ratio, and three types of complexes $\mathrm{LnL}_{2}, \mathrm{Ln}(\mathrm{HL})_{2}$, and $\mathrm{Ln}\left(\mathrm{H}_{2} \mathrm{~L}\right)_{2}$ are created inversely to the solid state where only one form of $\mathrm{Ln}\left(\mathrm{H}_{2} \mathrm{~L}\right)_{2}$ occurs. The diversity of the complexes in the solution is due to the fact that ligand $\left(\mathrm{H}_{2} \mathrm{~L}\right)$ occurs in solution in three forms: neutral $\left(\mathrm{H}_{2} \mathrm{~L}\right.$; undeprotonated), monodeprotonated $\left(\mathrm{HL}^{-}\right)$, and fully deprotonated $\left(\mathrm{L}^{2-}\right)$, depending on pH. UV-Vis spectra of $\mathrm{Ln}\left(\mathrm{H}_{2} \mathrm{~L}\right)_{2}$ and $\mathrm{Ln}(\mathrm{HL})_{2}$ complexes for all the studied systems are characterized by three main absorption bands which are assigned to the $\pi-\pi^{*}$ and $n-\pi^{*}$ transitions of the Schiff-base ligand. The maximum absorption of the band in the $\mathrm{Ln}^{3+} / \mathrm{H}_{2} \mathrm{~L}$ systems revealed only slight changes but absorption increases compared to the free ligand, and at $\mathrm{pH} 8$ the new absorption band appears for the ligand and for the studied systems. The new absorption band is formed due to the deprotonation of the phenolic $\mathrm{OH}$ groups of the ligand $\left(\mathrm{H}_{2} \mathrm{~L}\right)$. These complexes could be applied as potential antibacterial, antitumor or antifungal agents, and as catalysts.

Acknowledgements We would like to express our deep gratitude to Prof. Wanda Radecka-Paryzek for the opportunity to carry out these studies in her laboratory and for her precious advice. This work was supported by the Polish Ministry of Science and Higher Education [Grant Number N N204 127 039].

Open Access This article is distributed under the terms of the Creative Commons Attribution 4.0 International License (http://creativecommons.org/licenses/by/4.0/), which permits unrestricted use, distribution, and reproduction in any medium, provided you give appropriate credit to the original author(s) and the source, provide a link to the Creative Commons license, and indicate if changes were made.

\section{References}

1. M.T. Kaczmarek, R. Jastrząb, E. Hołderna-Kędzia, W. RadeckaParyzek, Inorg. Chim. Acta 362, 3127 (2009)

2. M. Fleck, D. Karmakar, M. Ghosh, A. Ghosh, R. Saha, D. Bandyopadhyay, Polyhedron 34, 157 (2011)

3. S.A. Matar, W.H. Talib, M.S. Mustafa, M.S. Mubarak, M.A. AlDamen, Arab. J. Chem. 8, 850 (2015)

4. P.G. Cozzi, Chem. Soc. Rev. 33, 410 (2004)

5. F. Rajabi, Tetrahedron Lett. 50, 395 (2009)

6. A.W. Kleij, Eur. J. Inorg. Chem. 2, 193 (2009)

7. L.F. Lima, M.L. Corraza, L. Cardoza-Filho, H. Màrquez-Alvarez, O.A.C. Antunes, Brazilian. J. Chem. Eng. 23, 83 (2006)

8. C. Papadopoulos, N. Kantiranis, S. Vecchio, M. Lalia-Kantouri, J. Therm. Anal. Calorim. 99, 931 (2010)

9. M. Layek, M. Ghosh, S. Sain, M. Fleck, P.T. Muthiah, S.J. Jenniefer, J. Ribas, D. Bandyopadhyay, J. Mol. Struct. 1036, 422 (2013)

10. Y.-N. Guo, L. Ungur, G.E. Granroth, A.K. Powell, C. Wu, S.E. Nagler, J. Tang, L.F. Chibotaru, Sci. Rep. 4, 5471 (2014)

11. Y.-N. Guo, G.-F. Xu, P. Gomez, L. Zhao, S.-Y. Lin, R. Deng, J. Tang, H.-J. Zhang, J. Am. Chem. Soc. 132, 8538 (2010)

12. Y.-N. Guo, G.-F. Xu, W. Wernsdorfer, L. Ungur, Y. Guo, J. Tang, H.-J. Zhang, L.F. Chibotaru, A.K. Powell, J. Am. Chem. Soc. 133, 11948 (2011)

13. P. Zhang, L. Zhang, C. Wang, S. Xue, S.-Y. Lin, J. Tang, J. Am. Chem. Soc. 136, 4484 (2014)

14. P. Zhang, Y.-N. Guo, J. Tang, Coord. Chem. Rev. 257, 1728 (2013)

15. L. Ungur, S.-Y. Lin, J. Tang, L.F. Chibotaru, Chem. Soc. Rev. 43, 6894 (2014)

16. P. Zhang, L. Zhang, J. Tang, Dalton Trans. 44, 3923 (2015) 
17. H. Wang, B.-W. Wang, Y. Bian, S. Gao, J. Jiang, Coord. Chem. Rev. 306, 195 (2016)

18. M. Shamsipur, S. Ershad, N. Samadi, A.R. Esmaeilbeig, R. Kia, A. Abdolmaleki, Electroanalytical 20, 1828 (2005)

19. R. Łyszczek, L. Mazur, Polyhedron 41, 7 (2012)

20. L. Wang, L. Ni, J. Yao, Solid State Sci. 14, 1361 (2012)

21. H. Wu, Y. Bai, Y. Zhang, G. Pan, J. Kong, F. Shi, X. Wang, Z. Anorg, Allg. Chem. 640, 2062 (2014)

22. Y. Sui, X.-N. Fang, R.-H. Hu, J. Li, D.-S. Liu, Inorg. Chim. Acta 423, 540 (2014)

23. R.-X. Chen, T. Gao, W.-B. Sun, H.-F. Li, H.-F. Wu, M.-M. Xu, X.-Y. Zou, P.-F. Yan, Inorg. Chem. Commun. 56, 79 (2015)

24. X. Yang, D. Lam, C. Chan, J.M. Stanley, R.A. Jones, B.J. Holliday, W.-K. Wohg, Dalton Trans. 40, 9795 (2011)

25. X. Yang, R.A. Jones, J.H. Rivers, W.-K. Wohg, Dalton Trans. 47, 10505-10510 (2009)

26. Y. Yue, P. Yan, J. Sun, G. Hou, G. Li, Polyhedron 94, 90 (2015)

27. G. Feng, L. Yu-Yang, L. Cai-Ming, L. Yi-Zhi, Z. Jing-Lin, Dalton Trans. 42, 11043 (2013)

28. L. Lekha, R.K. Kanmani, R. Hariharan, M. Sathish, G. Rajagopal, D. Easwaramoorthi, Appl. Organometalm Chem. 29, 90 (2015)

29. G. Tircsó, Z. Garda, F.K. Kálmán, Z. Baranyai, I. Pócsi, G. Balla, I. Tóth, J. Inorg. Biochem. 127, 53 (2014)

30. M.H. Irving, M.G. Miles, L.D. Petit, Anal. Chim. Acta 38, 475 (1967)

31. P. Stańczak, M. Łuczkowski, P. Juszczyk, Z. Grzonka, H. Kozłowski, Dalton Trans. 14, 2102 (2004)

32. P. Gans, A. Sabatini, A. Vacca, Talanta 43, 1739 (1996)

33. L. Alderighi, P. Gans, A. Lenco, D. Peters, A. Sabatini, A. Vacca, Coord. Chem. Rev. 184, 311 (1999)

34. R. Jastrzab, J. Inorg. Biochem. 103, 766 (2009)

35. R. Bregier-Jarzebowska, A. Gasowska, R. Jastrzab, L. Lomozik, Inorg. Biochem. 103, 1228 (2009)
36. M.T. Kaczmarek, M. Kubicki, Acta Crystallogr. Sect. B Struct. Sci. 70, $792(2014)$

37. R. Hernández-Molina, A. Mederos, P. Gili, S. Dominguez, F. Lioret, C. Jano, M. Julve, C. Ruiz-Pérea, X. Solans, J. Chem. Soc. Dalton Trans. 22, 4327-4334 (1997)

38. N. Galić, Z. Cimerman, V. Tomišić, Analytica Chim. Acta 343, 135 (1997)

39. S.N. Podyachev, I.A. Litvinov, A.R. Mustafa, R.R. Shagidullin, W.D. Habicher, A.I. Konovalov, Russ. Chem. Bull. 54, 623 (2005)

40. R.J. Montekaitis, A.E. Martel, Inorg. Chem. 27, 2718 (1988)

41. M.T. Kaczmarek, R. Jastrząb, W. Radecka-Paryzek, J. Solution Chem. 42, 18 (2013)

42. N.V. Pashchevskaya, S.N. Bolotin, M.E. Sokolov, A.A. Sklyar, V.T. Panyushkin, Russ. J. Gen. Chem. 76, 1015 (2006)

43. R. Janicki, P. Starynowicz, A. Mondry, Eur. J. Inorg. Chem. 24, 3601-3616 (2011)

44. H. Wang, R.M. Wen, T.L. Hu, Eur. J. Inorg. Chem. 7, 1185-1191 (2014)

45. M.T. Kaczmarek, R. Jastrząb, M. Kubicki, M. Gierszewski, M. Sikorski, Inorg. Chim. Acta 430, 108 (2015)

46. M.T. Kaczmarek, M. Kubicki, Z. Hantejko, Polyhedron 102, 224 (2015)

47. L.-M. Zneng, J.-X. Lui, J. Solid State Chem. 245, 45 (2017)

48. P.A. Mayer, K.C. Potgieter, T.I.A. Gerber, Polyhedron 29, 1423 (2010)

49. S. Bilge, Z. Kilic, Z. Hayvali, T. Hokelek, S. Safran, J. Chem. Sci. 121, 989 (2009)

50. H. Wang, P. Zhao, D. Shao, J. Zhang, Y. Zhu, Struc. Chem. 20, 995 (2009)

51. A. Sundar, M. Prabhu, G.N. Indra, M. Marappan, G. Rajagopal, Spectrochim. Acta A Mol Biomol. Spectroscopy 129, 509 (2014)

52. M. Meloun, V. Nečasová, M. Javůrek, T. Pekárek, J. Pharm. Biomed. Anal. 120, 158 (2016) 